\title{
Tapping Diversity From the Wild: From Sampling to Implementation
}

\author{
Sariel Hübner ${ }^{1 * \dagger}$ and Michael B. Kantar ${ }^{2 \dagger}$ \\ ${ }^{1}$ Galilee Research Institute (MIGAL), Tel-Hai College, Qiryat Shemona, Israel, ${ }^{2}$ Department of Tropical Plant and Soil \\ Sciences, University of Hawai'i at Mânoa, Honolulu, HI, United States
}

OPEN ACCESS

Edited by:

Petr Smýkal,

Palacký University Olomouc, Czechia

Reviewed by:

Clarice Coyne J.,

United States Department of Agriculture (USDA), United States Eric Von Wettberg, University of Vermont, United States

*Correspondence:

Sariel Hübner sarielh@migal.org.il

†These authors have contributed equally to this work

Specialty section: This article was submitted to Plant Breeding, a section of the journal

Frontiers in Plant Science

Received: 06 November 2020 Accepted: 07 January 2021 Published: 27 January 2021

Citation:

Hübner S and Kantar MB (2021) Tapping Diversity From the Wild: From Sampling to Implementation. Front. Plant Sci. 12:626565. doi: $10.3389 / \mathrm{fp} / \mathrm{s} .2021 .626565$
The diversity observed among crop wild relatives (CWRs) and their ability to flourish in unfavorable and harsh environments have drawn the attention of plant scientists and breeders for many decades. However, it is also recognized that the benefit gained from using CWRs in breeding is a potential rose between thorns of detrimental genetic variation that is linked to the trait of interest. Despite the increased interest in CWRs, little attention was given so far to the statistical, analytical, and technical considerations that should guide the sampling design, the germplasm characterization, and later its implementation in breeding. Here, we review the entire process of sampling and identifying beneficial genetic variation in CWRs and the challenge of using it in breeding. The ability to detect beneficial genetic variation in CWRs is strongly affected by the sampling design which should be adjusted to the spatial and temporal variation of the target species, the trait of interest, and the analytical approach used. Moreover, linkage disequilibrium is a key factor that constrains the resolution of searching for beneficial alleles along the genome, and later, the ability to deplete linked deleterious genetic variation as a consequence of genetic drag. We also discuss how technological advances in genomics, phenomics, biotechnology, and data science can improve the ability to identify beneficial genetic variation in CWRs and to exploit it in strive for higher-yielding and sustainable crops.

Keywords: crop wild relative, genetic drag, sampling design, introgression, breeding

\section{INTRODUCTION}

\section{Crop Wild Relatives-What Are They and What Benefit Do They Hold?}

More is expected from the world's food systems than at any previous time in human history (Godfray et al., 2010). The demands for food, fiber, fuel, and ecosystem services are increasing while climate perturbations are challenging agriculture production and geopolitical stability. Future projections models predict that major crops (e.g., maize, rice, wheat, soybean, and sunflower) will show increased vulnerability to these changes in many parts around the globe (Myers et al., 2017). Decreases in yield have already been reported (Ray et al., 2019) and are expected to escalate and narrow the extent of areas suitable for specific crops (Pironon et al., 2019). These changes can lead to the transformation of land uses and in extreme cases to the abandonment of previously cultivated regions (Estoque et al., 2019). 
Humans have domesticated hundreds of plant species over the millennia, transforming wild forms into a domesticate by fixing traits of importance in the agricultural system (Meyer et al., 2012; Purugganan, 2019). Over time, the domesticates have diverged remarkably from the wild form through a continuous process of selection for specific features while neglecting other adaptive traits. Crop wild relatives (CWRs) are generally defined as wild species that have some level of inter-fertility with a crop (Harlan and de Wet, 1971). While some of the domesticated plants have a multitude of cross-compatible congener wild species (e.g., sunflower; Kantar et al., 2015), others have very few (e.g., chickpea, fava bean, and quinoa; Castañeda-Álvarez et al., 2016). Historically, attempts to create a standard classification for CWR relied mostly on empirical crossing experiments (Harlan and de Wet, 1971) and resulted in four main germplasm categories: primary (no crossing barriers), secondary (mild crossing barriers), tertiary (requires special techniques such as embryo rescue), and quaternary (genetic engineering technics are required). Recent CWR germplasm classifications also consider the taxonomic information (Maxted et al., 2006) and evolutionary relationships (Miller and Khoury, 2018) when the knowledge on the crossing compatibility is limited. These classifications have helped to create strategies to prioritize germplasm collection efforts around the globe.

Subsequently, one of the major limitations of using CWR in breeding is hybridization barriers between undomesticated germplasm and the crop which increases along with evolutionary divergence (Viruel et al., 2020). Usually, crossing between the crop and the primary gene pool is the most convenient and allows to create large populations for selection. In many cases, the direct ancestral species of the crop occurs in a wide range of environments and holds ample genetic diversity to be explored for advantageous alleles (Anderson et al., 2016). However, even when hybridization between the wild and the domesticated forms is straightforward, genetic drag due to limited recombination may require a very long and costly process of purging linked and detrimental genetic variation. This process involves several generations of backcrossing to the cultivated parent over a long period when molecular markers are not available. The use of molecular markers can significantly accelerate this process (Iftekharuddaula et al., 2011), provided that the beneficial alleles were indeed identified in an available wild germplasm collection with high precision and confidence. For example, the use of molecular markers in maize breeding through a backcrossing scheme generated a benefit of over 130,000 US\$ compared with a conventional phenotypic scheme (Morris et al., 2003).

\section{Importance of Genebanks}

Wild germplasm that has been collected and conserved over the last century is already available in genebanks (Byrne et al., 2018). However, these germplasm repositories often lack specific geographic information, phenotypic characterization, and indications of disease and other stress resistances. Moreover, these collections represent a snapshot of allele frequencies resulting from the preceding environmental conditions to the time of collection. This incomplete information necessitates continued and increased efforts in CWR collection across the globe. With the advent of technology, it is now possible to identify beneficial genetic variation across space and time with more precision and allow genebanks to manage collections and reduce redundancy more efficiently (Milner et al., 2019).

A new CWR germplasm collection expedition usually begins with exploring the distribution of the species of interest. Nowadays, this information is available electronically which allows obtaining detailed geo-ecological information for a first survey (e.g., www.gbif.org and www.genesys-pgr.org). Moreover, performing species distribution model analysis based on observations of existing populations can provide indications also for potential unobserved occurrence of populations across the studied area (Williams et al., 2009). Among the most successful methods to identify potential regions where unknown populations may exist for collection and conservation is the gap analysis (Box 1) which has been used to explore the distribution of the most important CWR (Castañeda-Álvarez et al., 2016; Khoury et al., 2020). Despite its limitations, this approach has been used to identify species that are in dire need of conservation, identify geographic regions that may hold unknown populations, and gather information for landscape genomic studies (reviewed in Bragg et al., 2015). Sampling germplasm based on gap analysis and using this information in landscape genomics provides a powerful approach to identify alleles that are likely responsible for adaptation to abiotic stress (Table 1). However, this approach is usually constrained by the resolution of sampling and the associated information available on climate, soil, and metadata at each sampling location. Another potentially efficient method (see caveats below) for identifying beneficial genetic variation in CWR is focused identification of germplasm strategy (FIGS), which model environmental variables of known collection locations rather than formal species distribution modeling to locate populations of potential interest (Khazaei et al., 2013).

\section{Plant Collections Under the Nagoya Protocol}

To create a more equitable system for biological material sharing across the globe, several international agreements were established in the past decades. The convention of biological diversity (CBD) has been the main instrument to regulate and ensure national sovereignty over biological resources including propagation material of CWRs in contrast to the previous situation of free access and sharing (McCluskey et al., 2017). The CBD regulations took a turn in 2014 with the establishment of the Nagoya protocol which provides standard guidelines for the implementation of the CBD regulations regardless of if the country, where collections are made, has ratified it. To ensure that benefits from the use of a biological resource are shared with the providing countries, the Nagoya protocol requires that agreement between the relevant authorities of the provider and the user is in place. Although these regulations seem conceptually fair, they pose some difficulties that disrupt the collection and share of CWR germplasm collections. One difficulty is the ability to obtain permits from the authorities in some countries, especially in regions of civil unrest where some collection gaps of important CWR were identified. Many 


\begin{tabular}{|c|c|}
\hline Term & Definition \\
\hline Gap analysis & $\begin{array}{l}\text { A method to evaluate the representation of biodiversity in conservation repositories such as genebanks. This approach assists in } \\
\text { prioritizing efforts to collect and conserve biodiversity by identifying species that are underrepresented in genebanks collections (in situ } \\
\text { conservation) or geographic regions that were not thoroughly sampled (ex situ analysis). Gap analysis is mainly conducted for crop wild } \\
\text { relatives due to their applied importance. }\end{array}$ \\
\hline Linkage disequilibrium & $\begin{array}{l}\text { Association between alleles at two or more loci leading to higher frequency of dependence in segregation. Linkage disequilibrium is } \\
\text { pronounced in elite domesticated germplasm but is also observed in natural wild populations due to demographic and selective } \\
\text { constraints. The level of LD determines the resolution of mapping trait of interest in a segregating population or diversity panel. }\end{array}$ \\
\hline Introgression & $\begin{array}{l}\text { Transmission of genetic variation between individuals. Introgression relies on the crossing potential between the two individuals and also } \\
\text { on the recombination landscape around the target genomic region. }\end{array}$ \\
\hline Genetic drag & $\begin{array}{l}\text { The negative effects of linked genetic variation to the trait of interest. Introgression of genetic variation from one source (e.g., crop wild } \\
\text { relative) into a recipient variety involves a crossing step followed by consecutive backcrossing steps to recruit back the recipient variety } \\
\text { properties. Linkage disequilibrium between the targeted beneficial trait for introgression and a deleterious or unfavorable genetic } \\
\text { variation may "drag" the negative component and reduce the fitness of the hybrid. Strong linkage between the beneficial and negative } \\
\text { genetic variation will require much more effort to purge the "dragged" negative effect. }\end{array}$ \\
\hline Environmental stressor & $\begin{array}{l}\text { Any environmental factor that can have a negative impact on the plant fitness. The environmental stress can be abiotic like drought and } \\
\text { heat or biotic like disease or competition with other organisms. In many cases, stressors are correlated (abiotic and biotic) and their } \\
\text { impact on the plant fitness is complex, thus the underlying resistance or tolerance to stress may be a convolution of multiple } \\
\text { mechanisms. }\end{array}$ \\
\hline
\end{tabular}

times, the only accessible resource for genetic material is from historical collections preserved by different organizations around the world, yet the Nagoya protocol is vague regarding the share of historical germplasm collections; thus, the interpretation of different countries and organizations may be inconsistent and prevent sharing or use of highly beneficial material (Sherman and Henry, 2020). Germplasm collections that represent the distribution range of a species frequently cross the country jurisdiction, thus the bureaucratic burden involved in using a full germplasm collection may eventually prevent its implementation. Thus, the Nagoya protocol may in practice increase interest in genebank collections despite their caveats (see above) instead of establishing new, more traceable, and relevant collections. Finally, the effectiveness of the Nagoya protocol in the era of genome editing where actual crossing could be avoided is questionable, thus it seems that some adjustments to the regulations of biological material sharing are necessary in order to reach a balanced platform while maintaining the sovereignty of countries over their national resources.

\section{Using Crop Wild Relatives in Breeding}

Despite the wide phenotypic diversity observed among crop varieties, the majority of genetic diversity found in the wild did not pass the genetic bottleneck of domestication or was eroded later in strive for higher yields during the improvement phase. CWRs hold many benefits for breeding especially through the reintroduction of lost genetic diversity and new adaptive alleles that can increase crop production (Zamir, 2001; Hajjar and Hodgkin, 2007; Dempewolf et al., 2017). This genetic diversity is well recognized for its value in enhancing crop resilience to stress such as disease and drought and recently also for increasing yield and nutritional value (Khoury et al., 2015). For example, there has been a long history of using CWR to bring resistance genes into cultivated germplasm (Qi et al., 2016, 2019; Zhang et al., 2016; Singh, 2019), but also for improving nutritional value (Pfeiffer and McClafferty, 2007; Khoury et al., 2015; Syfert et al., 2016) and increasing yield components (Xiao et al., 1996; Gur and Zamir, 2004; Fernie et al., 2006). This approach has proven successful in many crops (Table 1) including major crops like maize and sunflower, where hundreds of lines harboring allele introgressions from CWR were released over the years (Warburton et al., 2017). While in some cases there have not been specific loci identified through introgression, many species have used wide-hybridization for crop improvement (Migicovsky and Myles, 2017). The strategy of using germplasm collections to improve cultivated plants has a long history and the use of molecular genetic information has been quite fruitful in both annual (Tanksley and McCouch, 1997; Gayacharan et al., 2020; Raubach et al., 2020) and perennial species (Aljane et al., 2018; Marcotuli et al., 2019; Migicovsky et al., 2019; Warschefsky and von Wettberg, 2019; Wang et al., 2020). Hence, CWRs have a tremendous value for plant breeding, with an annual impact of over 100 billion dollars estimated across global agriculture (Pimentel et al., 1997). Most efforts in exploiting CWR in breeding were dedicated to enhancing disease resistance and much less to enhance adaptation to abiotic stress (Dempewolf et al., 2017). However, the environment is constantly changing and breeding must respond at the same pace of change. Thus, identification and characterization of adaptive alleles in CWR is a prolonged process that needs to be framed efficiently using the power of genomics, phenomics, and advanced approaches in data analysis.

\section{STUDY DESIGN, SAMPLING, AND ANALYSIS}

The ultimate goal of collecting and exploring CWR is to identify genetic variants that contribute to adaptation in natural environments and can also be beneficial in agricultural systems. Thus, the motivation in this context is mainly to identify genes 
TABLE 1 | Studies that have identified alleles associated with abiotic stress in CWR.

\begin{tabular}{|c|c|c|c|c|c|}
\hline Species & Stress & Gene & Sampling design & Breeding strategy & References \\
\hline Glycine soja & Drought/heat & Glyma.08g298200 & Random sampling & Marker assisted backcrossing & Anderson et al., 2016 \\
\hline Glycine max & Drought/heat & Glyma.15g127700 & Random sampling & Marker assisted backcrossing & Bandillo et al., 2017 \\
\hline Glycine max & Annual precipitation & Glyma.15G196500 & Random sampling & Marker assisted backcrossing & Li et al., 2019 \\
\hline $\begin{array}{l}\text { Picea glauca and Picea } \\
\text { engelmannii }\end{array}$ & Temperature/aridity & 69_753 & Random sampling & N/A & De La Torre et al., 2014 \\
\hline Quercus lobata & Temperature/osmotic stress & Contig code name 42 and 57 & Transect & N/A & Sork et al., 2016 \\
\hline Pinus taeda & Aridity, temperature & EST contig 0-12 076n & Random sampling & N/A & Eckert et al., 2010 \\
\hline Triticum urartu & Temperature, precipitation, altitude & No specific gene & Random sampling & Marker assisted backcrossing & Brunazzi et al., 2018 \\
\hline Medicago truncatula & Temperature, salinity, drought, precipitation & Medtr3g029620 & Random sampling & N/A & Guerrero et al., 2018 \\
\hline $\begin{array}{l}\text { Zea mays ssp. Parviglumis and } \\
\text { Zea. mays ssp. mexicana }\end{array}$ & Temperature, precipitation & Genomic region & Transect & N/A & Pyhäjärvi et al., 2013 \\
\hline $\begin{array}{l}\text { Zea mays ssp. Parviglumis and } \\
\text { Zea. mays ssp. mexicana }\end{array}$ & Niche suitability & GRMZM2G164358 & Transect & N/A & Aguirre-Liguori et al., 2017 \\
\hline Hordeum vulgare & Temperature & HvPRR59 & Random sampling & $\begin{array}{l}\text { Marker assisted backcrossing, } \\
\text { genomic selection }\end{array}$ & Russell et al., 2016 \\
\hline Sorghum bicolor & Climate zones & Genomic region & Random sampling & Marker assisted backcrossing & Morris et al., 2013 \\
\hline Arabadopsis thaliana & Temperature & AT1G18140 & Paired sampling & $\begin{array}{l}\text { While this is not a crop, the genes } \\
\text { have become targets of selection in } \\
\text { other crops (e.g., pennycress) }\end{array}$ & Fournier-Level et al., 2011 \\
\hline Medicago truncatula & Temperature, precipitation & $7 g 074620.1$ & Random sampling & N/A & Yoder et al., 2014 \\
\hline Phaseolus vulgaris & Drought & Phvul.004G102800 & Random sampling & Marker assisted backcrossing & Ariani and Gepts, 2019 \\
\hline Phaseolus vulgaris & Temperature, precipitation & PvPdh1 & Random sampling & Marker assisted selection & Parker et al., 2019 \\
\hline Oryza sativa & Temperature & Genomic region & Cluster sampling & N/A & Qiu et al., 2017 \\
\hline Oryza glaberrima & Salt, temperature & OsHAK5 & Random sampling & Marker assisted selection & Meyer et al., 2016 \\
\hline Platycladus orientalis & Ecological niche & Genomic regions & Cluster sampling & $N / A$ & Jia et al., 2019 \\
\hline Triticum aestivum & Temperature & Genomic regions & Random sampling & $\begin{array}{l}\text { Marker assisted selection/genomic } \\
\text { selection }\end{array}$ & He et al., 2019 \\
\hline Eucalyptus microcarpa & Land use change & Genomic regions & Cluster sampling & N/A & Jordan et al., 2016 \\
\hline Mangifera spp. & Difference from cultivated & Genomic regions & Random SAMPLING & N/A & Wang et al., 2020 \\
\hline Solanum pimpinellifolium & Salt stress & Genomic regions and candidate genes & Transect sampling & Marker assisted selection & Gibson and Moyle, 2020 \\
\hline Cajanus cajan & Heat shock and disease resistance & Candidate genes & Random sampling & N/A & Rathinam et al., 2019 \\
\hline Triticum spp. & Agronomic Genes & Genomic regions and candidate genes & Random sampling & Marker assisted selection & He et al., 2019 \\
\hline Vitis vinifera & Difference from cultivated & Genomic regions & Random sampling & N/A & Migicovsky et al., 2016 \\
\hline Populus balsamifera & Climate niche & Genomic regions and structural variants & Transect sampling & N/A & Chhatre et al., 2019 \\
\hline Beta and Patellifolia spp. & Abiotic stress & Genomic regions & Random sampling & N/A & Monteiro et al., 2018 \\
\hline Oryza rufipogon & Abiotic stress & Genomic regions & Random sampling & Marker assisted selection & Li et al., 2020 \\
\hline Cicer reticulatum Ladiz & Cold tolerance & Genomic regions & Targeted sampling & Marker assisted selection & Mugabe et al., 2019 \\
\hline
\end{tabular}


and alleles with a potential benefit for crop breeding. Despite the contextual difference from ecological and evolutionary perspectives, the considerations, methodologies, and principles are akin. Generally, two types of approaches could be used to identify genes of interest in CWR: phenotype-independent approaches, such as genome scans (Lotterhos and Whitlock, 2015) and genome-environment association (GEA) analysis (Rellstab et al., 2015), and phenotype-dependent approaches including genome-wide association studies (GWAS) and QTL mapping (Stinchcombe and Hoekstra, 2008). Both types of approaches benefit from high-resolution genomic data and careful sampling design, yet each type of approach has its advantages and drawbacks that should be contemplated when searching for beneficial genetic variation in CWR.

\section{Sampling Designs}

Sampling designs impact all approaches attempting to identify beneficial genetic variation and therefore should be given considerable attention and planning (Selmoni et al., 2020). The sampling design should be adjusted according to the questions and objectives of the study (Figure 1) and the biology of the target species. One of the major confounding factors affecting the ability to identify beneficial genetic variation is the historical demography of the target species or population. This includes events of population expansion, genetic bottlenecks, recolonization, the mating strategy, and so forth. The demographic history of the species may lead to erroneous results due to a violation of the analytical model used to identify adaptive genetic variation. Moreover, the demographic history of a species is frequently correlated with environmental variation, thus distinguishing between the contribution of kinship and selective sweep to the genetic makeup may be difficult (Wright and Gaut, 2005). In the context of exploiting genetic variation obtained from CWR the objective is clear, identify genes and alleles that can enhance adaptation in crop species. The challenge is how to balance sampling across the species ecological variation to increase the chance of discovering precious genetic variation and avoid the confounding effect of past demography (Hoban et al., 2018). Different sampling strategies were examined and compared theoretically and empirically (Franco-Duran et al., 2019). Among the common strategies are transect sampling which allows representing genetic variation along ecological gradients, spatial random sampling which allows obtaining a balanced representation of the distribution range, structured sampling in demes and polygons which emphasizes the environmental variation within the distribution range, and paired-populations sampling which allows overcoming, in some cases, the confounding effects of shared demographic history (Hoban et al., 2016).

A key consideration in the sampling strategy is the number of genotypes that should be sampled to facilitate the identification of adaptive genetic variation. This is a probabilistic problem; more sampling will increase the chances of detecting beneficial genetic variation albeit with additional cost. Formerly, genotyping was the main limiting factor for sample size; however, advent in genomic sequencing technologies has made ultrahigh throughput genotyping accessible; hence, genotyping a large number of individuals is now affordable (Jaworski et al., 2020). The next-generation sequencing revolution has made genome scans and GEA methods highly attractive for identifying beneficial genetic variation while genomic mapping approaches that also require high-quality phenotypic data were faced with a quickly expanding genotype-phenotype gap (Table 2). This gap is now being filled with high-throughput phenotypic data that are generated in advanced infrastructures where plants are screened and measured continuously, yet approaches for screening plants under field conditions are still rather limited and should receive more attention (Yang et al., 2020).

Environmental heterogeneity along space requires that sampling of individuals will properly represent the ecological gradient across the distribution range including the extremes. Occasionally, substantial adaptive genetic variation can be obtained from a single sampling location where micro-climatic conditions result in a range of environmental stressors within the same population. Moreover, theory predicts that adaptive genetic variation could also be obtained across different time points because non-random dispersion will lead to some level of environmental heterogeneity (Lynch and Ho, 2020). Thus, sampling a population without considering the site spatial and temporal variation may fail to represent the available adaptive genetic variation and introduce some bias at the exact location and timing of sampling. A tempting strategy is to sample a few populations where a high chance to identify genetic variation that is contributing to the trait of interest is expected (e.g., FIGS; Khazaei et al., 2013). Although expedient, this approach has several drawbacks. For example, sampling along a narrow geographic range can increase the rate of false-positive signals due to increased relatedness among neighboring populations. The limited geographic range and ecological variation represented may deteriorate the effectiveness of GEA and genome scans approaches. However, if enough genetic variation could be sampled, genome mapping approaches may gain power from a targeted sampling design due to the reduced effect of population structure.

Clearly, the sampling strategy and the subsequent analytical approach should be planned with much attention to the ecological and genetic characteristics of the target species. While abundant species can benefit from sampling across a spectrum of environmental gradients, species that are characterized by a constrained distribution may require an adjusted strategy of temporal repeated sampling or fine-resolution sampling of microenvironments to allow exploring the breadth of genetic variation.

\section{Analytical Approaches to Identify Beneficial Genetic Variation}

Implementation of beneficial genetic variation obtained from CWR in breeding often requires identifying the causative mutation or tightly linked polymorphism to the trait of interest in the wild germplasm. Analytical approaches to identify the genetic variation of interest can be divided between approaches where phenotypic data are not mandatory (phenotype-independent) and approaches that rely on high-quality phenotypic data 

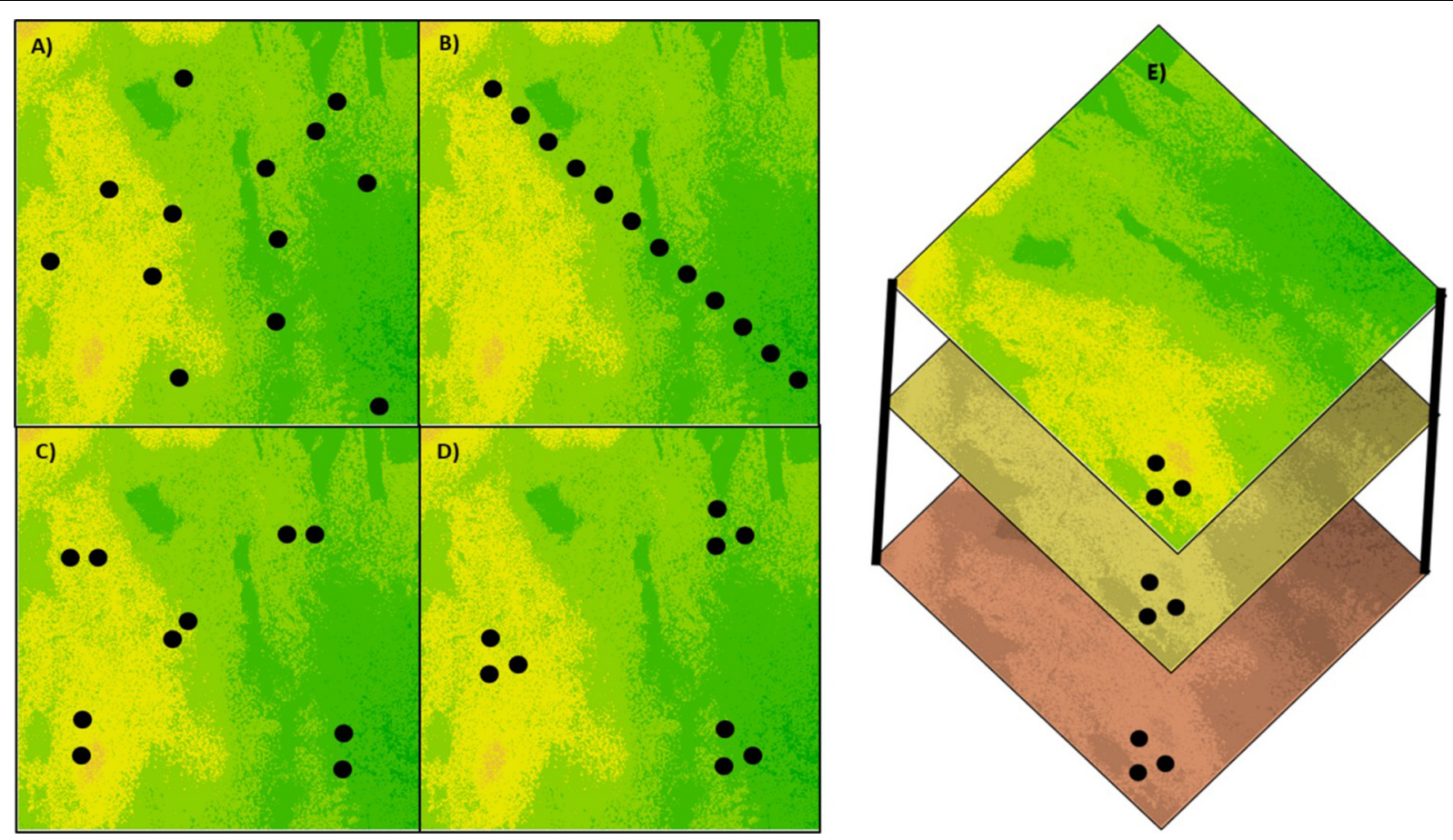

FIGURE 1 | Types of sampling designs for creating CWR germplasm collections. (A) Random sampling to obtain an uniform and unbiased representation of a heterogeneous environment, (B) transect sampling to represent the variation along an environmental gradient, (C) paired sampling in a heterogeneous environment to reduce the demographic effect on differentiation between populations, (D) clustered sampling to represent the within-site variation in comparison between sites, and $(\mathbf{E})$ sampling at the same geographic location over different seasons or time points to represent changes in allele frequencies over time.

(phenotype-dependent). A short list of tools and packages is provided as an example in Table 2.

The phenotype-independent approaches do not consider the underlying trait of interest explicitly and allow to avoid laborious phenotyping experiments. This has the advantage of gaining statistical power by screening a large number of individuals and populations for signs of adaptation along the genome. Advent in genome sequencing platforms makes high-resolution genotyping for a large number of individuals accessible in a reasonable time frame and cost (Halewood et al., 2018; Jaworski et al., 2020), thus enough statistical power can be obtained to identify genomic regions of interest using these a priori genome screening approaches. Genome scan methods are conducted by calculating population genetics statistics using a sliding window frame in a target population (Table 2). The calculated statistics can indicate the level of diversity, linkage disequilibrium, skewness in the site frequency spectrum, or the level of differentiation between contrasting populations. Outlier scores at specific windows are interpreted as candidate regions where selective sweep in response to environmental stress occurred. These methods are highly prone to false-positive outliers due to violations of the underlying assumptions which are frequent in natural populations (Lotterhos and Whitlock, 2015; Hoban et al., 2016). The high rate of false-positive signals can partially be controlled by combining the scores or $p$-values obtained for different statistics (Lotterhos et al., 2017). However, a proper sampling scheme can significantly improve the power and accuracy of these methods (Lotterhos and Whitlock, 2015). For example, sampling pairs of populations from contrasting environmental conditions (e.g., dry/wet) and in different geographic regions can allow identifying overlapping adaptive genetic variation while controlling the demographic effect using genome scans between each pair and comparing the results obtained from a different geographic region.

Another approach to identifying genomic regions that contribute to adaptation across environmental gradients is a GEA. Like genome scans, this approach benefits from highresolution genotyping and avoids the laborious phenotyping procedure. However, unlike genome scan methods, GEA also requires complementary environmental data. This type of information can now be obtained easily from international open databases (e.g., Fick and Hijmans, 2017), yet the data are usually derived from interpolations calculated across distant monitoring stations and averaged over long periods. Clearly, these data smooth over local extreme conditions and may poorly represent spatial and temporal heterogeneity in environmental conditions (Rellstab et al., 2015). In addition, GEA is strongly affected by spatial auto-correlation and the results may be falsely interpreted due to covariance with another, perhaps more important, environmental factor. For example, dry and warm conditions are frequently geographically correlated, thus signs of genomic associations along a drought gradient may also be obtained from genes that are contributing to the 


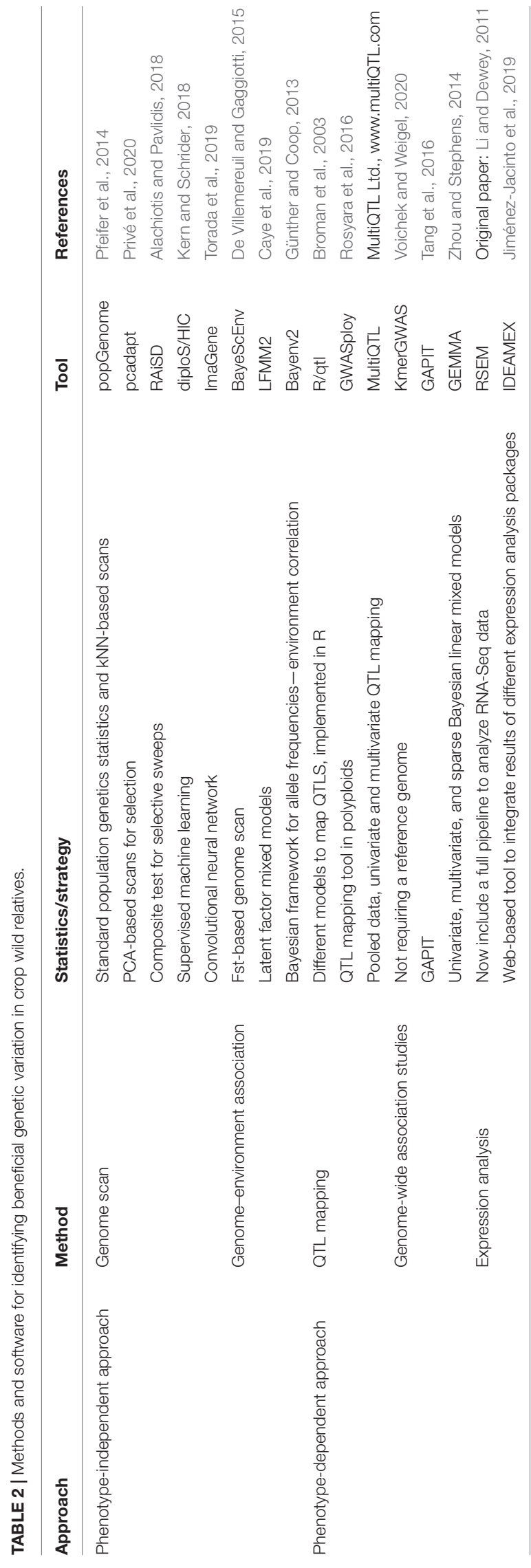

correlated response to heat. Other factors that increase the rate of false-positive signals in genome scans methods are also notable in GEA and include violations of the model assumptions, confounding effect of demographic processes, and ascertainment bias in polymorphism detection (Bragg et al., 2015; Rellstab et al., 2015).

The second type of approach used to identify beneficial genetic variation in CWR is genomic mapping using QTL analysis in a population that was generated from crosses, and GWAS conducted in a diversity panel (Table 2). To use these methods, a mapping population should be developed by selecting a representative panel of accessions for GWAS or by conducting crosses between individuals harboring specific features. Genomic mapping approaches are compelling because they target the genetic features that are contributing directly to the trait of interest as measured in controlled experimental design. These methods are generally powerful once the confounding effects of population structure and relatedness are controlled in the model, the multiple-testing effect on $p$-values inflation is corrected, and sufficient individuals are included (Korte and Farlow, 2013). Despite their effectiveness, these methods require intensive phenotyping which can be laborious and prone to noise, especially if conducted under field conditions. Other experimental facilities such as greenhouses and growth chambers are affected less by experimental variation but are concurrently less predictive for field conditions, specifically when strong genome-environment interactions exist (Tardieu et al., 2017).

Both GWAS and linkage mapping require high-resolution genotype and phenotype data for the mapping population. It is possible to use several crossing designs to generate a mapping population including a bi-parental cross between a wild accession and a modern cultivar and a multi-parental cross between several wild accessions and one or more domesticated types (Tanksley and McCouch, 1997; Meng et al., 2016). Although the mapping resolution obtained from crosses is usually low due to the limited number of recombination events observed over few generations, this approach has the great benefit of introducing novel genetic variation into elite material and generating the first phase toward the implementation of wild adaptive variation in breeding. Nevertheless, crossing CWR and modern cultivars can be challenging due to crossing barriers. These barriers increase with the divergence between the wild germplasm and the cultivated lines, thus crosses with the primary gene pool have the highest (or sometimes the only) chance of producing a viable offspring for subsequent implementation through breeding.

Another powerful approach to identify beneficial genetic variation in wild germplasm is conducting a differential expression analysis between wild and cultivated accessions or between wild accessions exposed to different treatments (Hübner et al., 2015). This approach has the benefit of handling a small number of accessions to focus on the trait of interest and the underlying genes. However, prior knowledge is required on the exact timing and tissue where the relevant genes are expressed and indications of the plausible identity of these genes. Otherwise, it is challenging to distinguish, based on the 
differential expression profile alone, between genes that truly contribute to the trait of interest and those of only mild effect (Azodi et al., 2020).

\section{FROM SURVEY TO IMPLEMENTATION}

\section{Introgression of Beneficial Traits}

In many crop species, yields are starting to plateau presumably due to erosion of genetic variation (albeit there are also other reasons) that hinders adaptation to increasing environmental stress. Therefore, enhancing adaptation in elite varieties by introgression of new genetic variation from wild relatives is a promising venture. Introgression of beneficial genetic variation from CWR is not a new concept, and there have been many successful attempts to enhance adaptation mainly through increasing biotic and abiotic stress tolerance in various crop species (Hajjar and Hodgkin, 2007; Sharma and Upadhyaya, 2016; Hübner et al., 2019; Szymañski et al., 2020). Some of the well-known examples include rust resistance in wheat (Autrique et al., 1995), cytoplasmic male sterility in sunflower (Rieseberg et al., 1994), and submergence tolerance in rice (Xu et al., 2006). Nevertheless, introgression comes with a burden as linked deleterious genetic variation often accompanies the trait of interest causing a genetic drag. To achieve a successful integration of a beneficial trait while minimizing the associated genetic drag, the recombination landscape at the region of introgression should be explored. Although many introgressions from wild germplasm have resulted in a substantial non-recombining haplotype (Baute et al., 2015), it is unclear to what extent the deleterious effect of genetic drag deteriorates the performance of the recipient cultivar.

In eukaryotes, the recombination rate varies significantly across species, populations, and individuals. The recombination rate also varies across the chromosome which appears as regions of elevated recombination (hot-spots) or suppressed recombination (cold-spots) along the genome. Likewise, recombination landscape varies between crop species and their wild relatives, thus recombination hot-spots and cold-spots do not necessarily occur at overlapping positions in both species (Dreissig et al., 2019). Introgression is also affected by the recombination landscape along the genome. First, regions of homology tend to recombine more, thus the higher the homology between species the higher the chance for successful introgression (Canady et al., 2006). This correlation between homology and introgression advocates the use of the primary gene pool for identification of beneficial genetic variation and as the source of introgression, preferably from the ancestral population of the crop species, if known.

Second, introgression from a congener species through hybridization and backcrossing could be efficiently cleaved in recombination hot-spots and consequently purged by selection. Hence, the deleterious effect of genetic drag can be depleted efficiently while the beneficial allele is fixed (Blary and Jenczewski, 2019). Nevertheless, if the beneficial trait is attributed to linked alleles that are passed together to the recipient genotype, a high recombination rate at the introgression region can also break this advantageous linkage (Sachdeva and Barton, 2018). Targeting the introgression to a recombination hotspot may be difficult and depends largely on the homology and the recombination landscape of both the recipient and donor individuals. Moreover, the introgression itself can have a dramatic effect on the recombination landscape around the introgression region in the recipient species (Rodgers-Melnick et al., 2015). In crops where double haploid production protocols are established, a genotype could be fixed at a homozygote state quickly once the introgressed region around the beneficial variant is minimized (Daurova et al., 2020). The development of high-resolution markers that are tightly linked to the causative mutation is important to track the course of introgression throughout the breeding process. Nevertheless, evidence for the contribution of structural variation such as inversions, insertions, and deletions to adaptation is accumulating in many crop species (Zhou et al., 2019; Alonge et al., 2020; Todesco et al., 2020; Walkowiak et al., 2020). Increasing the resolution of molecular markers within these regions would yield little benefit because recombination within those regions is rare.

As the ultimate goal is to be able to introgress the traits into a breeding material, sampling ecotypes that are very diverged from the cultivated gene pool may pose challenges to successful introgression of the anticipated beneficial genetic variation. Thus, identifying the progenitor wild population of the cultivated gene pool or at least the genetically closest can be critical for an efficient and successful introgression. Due to local environmental variation, beneficial alleles could potentially also be found in a genetically closer population to the cultivated gene pool (Hübner et al., 2015). The higher genetic resemblance between the crop and its wild relative can potentially reduce the genetic drag and the deleterious effect of background selection in the wild source.

Another consideration for the implementation of CWR in crop improvement is the breeding strategy of the target species. In many crops, breeders are crossing distinct inbred parents to produce a hybrid variety with increased vigor and yield. In these cases, the interaction between the introgressed wild allele and the cultivated allele at the adaptive gene should also be considered. Overdominance heterotic interactions are difficult to predict in advance and, in some cases, dominance of the cultivated allele may mask the effect of the wild allele. Nevertheless, at least some of the heterotic effects observed in hybrid crops are caused by genetic complementation from the wild parent (Owens et al., 2019), thus allowing to exploit effectively beneficial genetic variation from CWR. Another level of complexity in introgression of beneficial genetic variation from CWR is when the target species is a polyploid. The potential genome asymmetry should also be considered on top of all other factors described for diploid species. These considerations are further complicated when there are ploidy differences between the donor and recipient species (Viruel et al., 2020). Unlike annuals crops, introgression of alleles from CWR in perennial species is more challenging due to the long generation time. However, once a beneficial 
successful introgression is observed in breeding material, maintenance of the new variety is potentially simpler if clonal propagation is possible.

\section{Direct Uses of Crop Wild Relatives}

Domestication is a long endeavor, which includes the fixation of many quantitative traits. Therefore, to develop a fully domesticated crop from a wild species, a long breeding process is required before all domestication syndrome traits are fixed and acceptable yields and biomass are obtained. Thus, it is not surprising that only a few plant species went through a complete process of domestication to meet modern agriculture standards (Stetter et al., 2017). Among the successfully domesticated species are the 15 major crops cultivated today around the globe, which provide circa $70 \%$ of the calories in human nutrition (Khoury et al., 2014). Interestingly, half of the calories produced globally are acquired from the three major annual crops, i.e., wheat, rice, and maize (Ladha et al., 2016). Although only a few species went through the entire process of domestication and improvement, many other species were only partially domesticated (e.g., Kiwiberry-Hale et al., 2018; PennycressChopra et al., 2020). Obviously, these crops cannot compete with the high yields of the elite crops, yet they hold many nutritional and adaptive advantages as they can be cultivated in a wide range of environments with less agronomic input and lower ecological footprint (Fernie and Yan, 2019). Moreover, semi-domesticated crops are characterized by higher local adaptation at specific environments compared with elite crop varieties specifically at regions where elite cultivars have low suitability and require intensive investment to produce high yields.

Two routes of domestication can be pursued: re-domestication of a wild form of an existing domesticated crop and de novo domestication (e.g., the Eastern North American domestication complex; Mueller et al., 2017) of a species that has never been successfully domesticated or that has been domesticated before but for a different purpose (Fernie and Yan, 2019). Re-domestication of CWRs has the benefit of having a reference of a previous success, namely, domestication of the target species is indeed possible and the domestication syndrome traits are known. Accordingly, advanced biotechnology including transformation and gene editing is emerging as attractive techniques to target domestication syndrome traits to develop a domesticated crop (Lemmon et al., 2018). This biotechnological approach can potentially avoid the deleterious effect of genetic drag that is frequently associated with classical breeding. It is tempting to speculate that if a super-gene is targeted and modified, a more concrete domesticated phenotype could be obtained in a few laboratory steps. Another route is de novo domestication of a wild species that was not successfully domesticated before but has specific properties that make it commercially attractive (Fernie and Yan, 2019). Certainly, this is a long process that could span over many generations if a fully domesticated form is desirable. However, the process could be shortened significantly if directed at specific use such as the production of valuable metabolite, chemical compound, highly nutritional component, and so forth (Pinela et al., 2017). Domestication approaches are particularly useful in perennial species with long generation times. Selected wild accessions could be used as a founder breeding population and optimized through the application of genomic selection of desired and beneficial traits (Cooper et al., 2016).

\section{FUTURE DIRECTIONS}

\section{Advancement in Genomics}

In the last two decades, the field of genomics has made a quantum leap making genome sequencing of any organism affordable and accessible. CWRs with large and repetitive genomes can now be sequenced at large scale and reference genomes could be assembled within months (including polyploid and outcrossing species). Other levels of genetic variation, including gene inversions, deletions, insertions, and duplications, are emerging as key factors in evolutionary biology and the generation of phenotypic variation within breeding material (Hübner et al., 2019; Tao et al., 2019; Alonge et al., 2020). Thus, high-resolution genomic characterization is no longer the limiting factor in targeting beneficial genetic variation in CWR. In contrast, high-quality phenotype data for CWR that were generated under field or controlled conditions are still rather limited, but availability is increasing (Raubach et al., 2020). Setting large phenotyping experiments for wild germplasm is challenging, yet the unprecedented benefit for the scientific and breeding community should encourage more investment and attention. With the advent of technology, large phenotyping experiments become more applicable, thus data collecting and sharing standards should be established to allow accessible archiving and pulling of information through public repositories (Zamir, 2001). The recent biotechnological breakthrough of genome editing engineering toolkit such as CRISPR is expected to dramatically impact the implementation of genetic variation identified in CWR. Genome editing has the advantage of targeting precisely the genomic factors to be edited and helps to avoid many generations of backcrossing to reduce the negative effect of genetic drag and potentially also circumvent crossing barriers. Genome editing could be used to manipulate both qualitative and quantitative traits (Chen et al., 2019) following the beneficial genetic variation identified in CWR. Editing protocols involve transformation and tissue culturing steps which could be challenging in some crops. However, active research and developments may circumvent these steps and allow the implementation of this technology beyond specific genotypes and species and make it applicable more broadly (e.g., bombardment, nano-particles; Kausch et al., 2019). Moreover, in cases where the transition from a wild phenotype to a domesticate involves a small set of genes, genome editing could be used to de novo domesticate wild species in a short timeframe (Lemmon et al., 2018).

\section{Advancement in Data Collection and Analysis}

Data collecting technologies are emerging as interesting means to monitor phenotypes in large-scale field trials. 


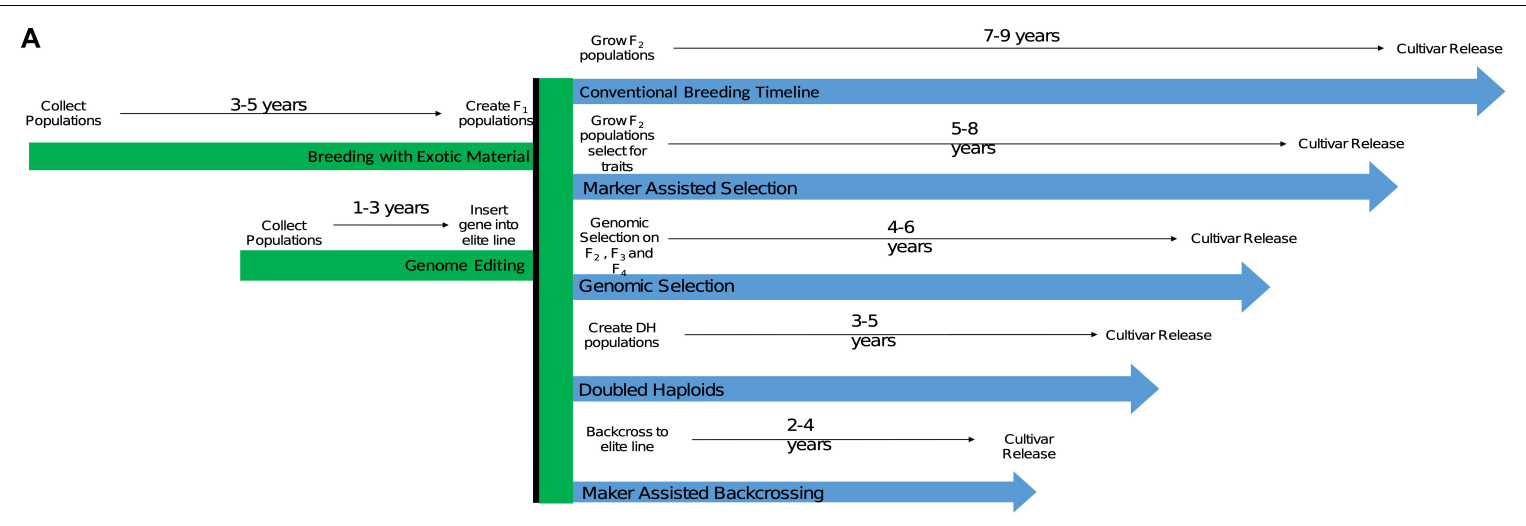

B

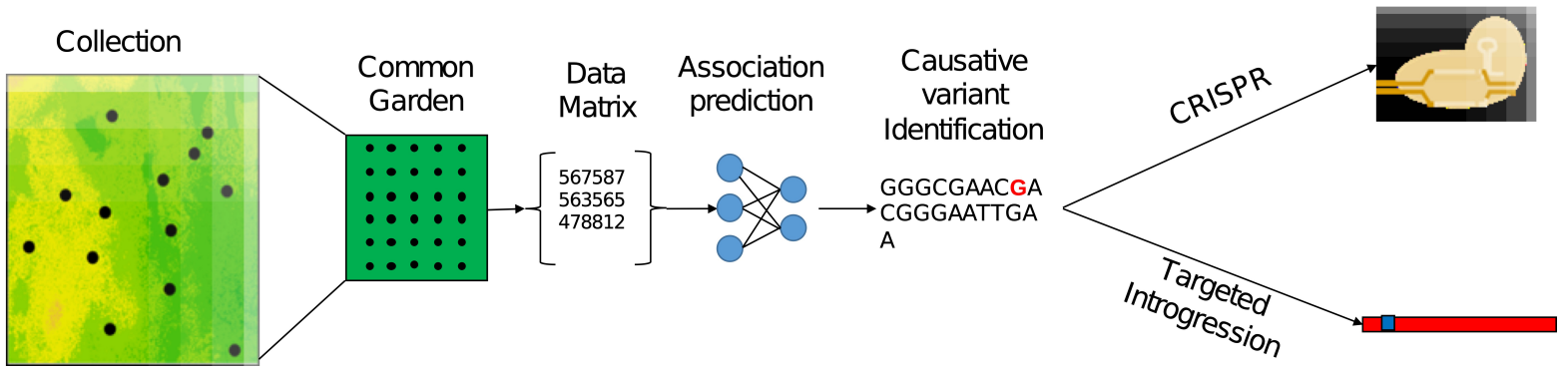

FIGURE 2 | The process of implementing beneficial genetic variation identified in CWR in breeding. (A) Expected breeding timeline for different breeding strategies leveraging beneficial genetic variation that was already targeted in CWR. The given time frames are for annual crop breeding without the use of accelerating conditions such as greenhouse or winter nursery. (B) A conceptual pipeline for leveraging genetic variation identified in CWR in breeding, from sampling design and collection, followed with a common garden experiment for phenotyping, analysis of genomic, phenomic, and environmental data to target the causative mutation or tightly linked polymorphism. Once the trait was targeted gnomically, implementation into breeding material could be conducted through direct genome editing (CRISPR) or introgression.

Moreover, the integration of continuous data recording instruments and remote sensing devices is now allowing researchers and breeders to monitor and perform detailed phenotyping of CWR in their natural habitats (Rebetzke et al., 2019). In the past few years, a powerful data analysis approach to leverage high dimensionality data using machine learning (ML) algorithms has gained considerable attention. Although this approach is still in its infancy in the field of quantitative and population genetics, it is quickly emerging as an accurate predicting tool that can overcome some of the unrealistic assumptions of population genetics models (Schrider and Kern, 2018). Algorithms to identify footprints of selective sweeps in natural populations and genotypephenotype associations are becoming available for the community (Table 2). These analytical tools are expected to significantly improve the predictability of the causative mutation(s) through post hoc analysis especially in complex traits (Ramstein et al., 2019; Nicholls et al., 2020). Other applications of ML algorithms can help to accelerate the breeding process through the implementation of deep learning methods in phenotyping, genomic selection, prediction of functionality, and so forth (reviewed in Wang et al., 2019). Rapid technological advances in data production and analysis can facilitate the use of CWR in breeding more broadly than before (Figure 2).
Genomic and phenomic data could now be generated in large quantities and reasonable budget, thus the genotypephenotype gap is quickly shrinking thanks to technology (Prohens et al., 2017; Yang et al., 2020). This has a substantial impact on the use of CWR in breeding because traits can be efficiently targeted, transferred, and fixed in cultivated material. Thus, identification of beneficial genetic variation in nature using $\mathrm{ML}$ algorithms will allow developing crop ideotypes at a much higher pace than ever before and the value of these resources will only increase over time.

\section{CONCLUSION}

Crop wild relatives have long been recognized as a highly valuable resource of genetic variation that could be exploited in breeding. Many examples of successful implementation of wild genetic variation in breeding exist yet much more could be exploited to improve the nutritional value of crops, increase their resilience to biotic and abiotic stress, and enhance their economic yield. Targeting beneficial genetic variation in nature is challenging and requires a careful sampling design that considers the ecological and evolutionary properties of the target species. Advent in high-throughput genotyping technology coupled with ongoing 
developments in computation power and machine-learning algorithms is allowing to identify beneficial genetic variation in CWR at the finest resolution. Thus, the implementation of wild genetic variation in breeding is expected to increase in the near future thanks to the ability to narrow the introgressed region and reduce the effect of genetic drag. Genome editing technology is quickly emerging as a promising approach to introduce beneficial genetic variation and avoid some of the complications associated with crossing. Although this technology is still not fully functional in many crop species, new protocols are emerging, thus CWRs are becoming more relevant for breeding than ever before.

\section{REFERENCES}

Aguirre-Liguori, J. A., Tenaillon, I., Vázquez-Lobo, A., Gaut, B. S., JaramilloCorrea, J. P., Montes-Hernandez, S., et al. (2017). Connecting genomic patterns of local adaptation and niche suitability in teosintes. Mol. Ecol. 26, 4226-4240. doi: $10.1111 / \mathrm{mec} .14203$

Alachiotis, N., and Pavlidis, P. (2018). RAiSD detects positive selection based on multiple signatures of a selective sweep and SNP vectors. Commun. Biol. 1, $1-11$.

Aljane, F., Essid, A., and Nahdi, S. (2018). "Improvement of Fig (Ficus carica L.) by Conventional Breeding and Biotechnology," in Advances in Plant Breeding Strategies: Fruits, eds S. M. Jain, J. M. Al-Khayri, and D. V. Johnson (Cham: Springer), 343-375. doi: 10.1007/978-3-319-91944-7_9

Alonge, M., Wang, X., Benoit, M., Soyk, S., Pereira, L., Zhang, L., et al. (2020). Major impacts of widespread structural variation on gene expression and crop improvement in tomato. Cell 182, 145-161. doi: 10.1016/j.cell.2020. 05.021

Anderson, J. E., Kono, T. J., Stupar, R. M., Kantar, M. B., and Morrell, P. L. (2016). Environmental association analyses identify candidates for abiotic stress tolerance in Glycine soja, the wild progenitor of cultivated soybeans. G3 Genes Genomes Genet. 6, 835-843. doi10.1534/g3.116.026914

Ariani, A., and Gepts, P. (2019). Signatures of environmental adaptation during range expansion of wild common bean (Phaseolus vulgaris). BioRxiv 2019:571042.

Autrique, E., Tanksley, S. D., Sorrells, M. E., and Singh, R. P. (1995). Molecular markers for four leaf rust resistance genes introgressed into wheat from wild relatives. Genome 38, 75-83. doi: 10.1139/g95-009

Azodi, C. B., Pardo, J., VanBuren, R., de los Campos, G., and Shiu, S. H. (2020). Transcriptome-based prediction of complex traits in maize. Plant Cell 32, 139-151. doi: 10.1105/tpc.19.00332

Bandillo, N. B., Anderson, J. E., Kantar, M. B., Stupar, R. M., Specht, J. E., Graef, G. L., et al. (2017). Dissecting the genetic basis of local adaptation in soybean. Sci. Rep. 7:17195.

Baute, G. J., Kane, N. C., Grassa, C., Lai, Z., and Rieseberg, L. H. (2015). Genome scans reveal candidate domestication and improvement genes in cultivated sunflower, as well as post-domestication introgression with wild relatives. N. Phytol. 206, 830-838. doi: 10.1111/nph.13255

Blary, A., and Jenczewski, E. (2019). Manipulation of crossover frequency and distribution for plant breeding. Theoret. Appl. Genet. 132, 575-592. doi: 10. 1007/s00122-018-3240-1

Bragg, J. G., Supple, M. A., Andrew, R. L., and Borevitz, J. O. (2015). Genomic variation across landscapes: insights and applications. N. Phytol. 207, 953-967. doi: $10.1111 / \mathrm{nph} .13410$

Broman, K. W., Wu, H., Sen, Ś, and Churchill, G. A. (2003). R/qtl: QTL mapping in experimental crosses. Bioinformatics 19, 889-890. doi: 10.1093/bioinformatics/ btg112

Brunazzi, A., Scaglione, D., Talini, R. F., Miculan, M., Magni, F., Poland, J., et al. (2018). Molecular diversity and landscape genomics of the crop wild relative Triticum urartu across the Fertile Crescent. Plant J. 94, 670-684. doi: 10.1111/ tpj.13888

\section{AUTHOR CONTRIBUTIONS}

Both authors listed have made a substantial, direct and intellectual contribution to the work, and approved it for publication.

\section{FUNDING}

This research was supported by a Research Fellowship Award No. FR-38-2019 from BARD, the United States-Israel Binational Agricultural Research and Development Fund, and the Israel Science Foundation (ISF) Grant No. 1154/19.

Byrne, P. F., Volk, G. M., Gardner, C., Gore, M. A., Simon, P. W., and Smith, S. (2018). Sustaining the future of plant breeding: The critical role of the USDAARS National Plant Germplasm System. Crop Sci. 58, 451-468. doi: 10.2135/ cropsci2017.05.0303

Canady, M. A., Ji, Y., and Chetelat, R. T. (2006). Homeologous recombination in Solanum lycopersicoides introgression lines of cultivated tomato. Genetics 174, 1775-1788. doi: 10.1534/genetics.106.065144

Castañeda-Álvarez, N. P., Khoury, C. K., Achicanoy, H. A., Bernau, V., Dempewolf, H., Eastwood, R. J., et al. (2016). Global conservation priorities for crop wild relatives. Nat. Plants 2, 1-6.

Caye, K., Jumentier, B., Lepeule, J., and François, O. (2019). LFMM 2: Fast and accurate inference of gene-environment associations in genome-wide studies. Mol. Biol. Evol. 36, 852-860. doi: 10.1093/molbev/msz008

Chen, K., Wang, Y., Zhang, R., Zhang, H., and Gao, C. (2019). CRISPR/Cas genome editing and precision plant breeding in agriculture. Annu. Rev. Plant Biol. 70, 667-697. doi: 10.1146/annurev-arplant-050718-100049

Chhatre, V. E., Fetter, K. C., Gougherty, A. V., Fitzpatrick, M. C., Soolanayakanahally, R. Y., Zalensy, R. S., et al. (2019). Climatic niche predicts the landscape structure of locally adaptive standing genetic variation. BioRxiv:817411. Preprint.

Chopra, R., Johnson, E. B., Emenecker, R., Cahoon, E. B., Lyons, J., Kliebenstein, D. J., et al. (2020). Identification and stacking of crucial traits required for the domestication of pennycress. Nat. Food 1, 84-91. doi: 10.1038/s43016-0190007-z

Cooper, M., Technow, F., Messina, C., et al. (2016). Use of crop growth models with whole-genome prediction: application to a maize multienvironment trial. Crop Sci. 56, 2141-2156. doi: 10.2135/cropsci2015.08.0512

Daurova, A., Daurov, D., Volkov, D., Zhapar, K., Raimbek, D., Shamekova, M., et al. (2020). Doubled haploids of interspecific hybrids between Brassica napus and Brassica rapa for canola production with valuable breeding traits. OCL 27:45. doi: 10.1051/ocl/2020041

De La Torre, A. R., Roberts, D. R., and Aitken, S. N. (2014). Genome-wide admixture and ecological niche modeling reveal the maintenance of species boundaries despite long history of interspecific gene flow. Mol. Ecol. 23, 20462059. doi: $10.1111 / \mathrm{mec} .12710$

De Villemereuil, P., and Gaggiotti, O. E. (2015). A new FST-based method to uncover local adaptation using environmental variables. Methods Ecol. Evol. 6, 1248-1258. doi: 10.1111/2041-210x.12418

Dempewolf, H., Baute, G., Anderson, J., Kilian, B., Smith, C., and Guarino, L. (2017). Past and future use of wild relatives in crop breeding. Crop Sci. 57, 1070-1082. doi: 10.2135/cropsci2016.10.0885

Dreissig, S., Mascher, M., and Heckmann, S. (2019). Variation in recombination rate is shaped by domestication and environmental conditions in barley. Mol. Biol. Evol. 36, 2029-2039. doi: 10.1093/molbev/msz141

Eckert, A. J., Van Heerwaarden, J., Wegrzyn, J. L., Nelson, C. D., Ross-Ibarra, J., Gonzalez-Martinez, S. C., et al. (2010). Patterns of population structure and environmental associations to aridity across the range of loblolly pine (Pinus taeda L., Pinaceae). Genetics 185, 969-982. doi: 10.1534/genetics.110.115543

Estoque, R. C., Gomi, K., Togawa, T., Ooba, M., Hijioka, Y., Akiyama, C. M., et al. (2019). Scenario-based land abandonment projections: Method, application 
and implications. Sci. Total Environ. 692, 903-916. doi: 10.1016/j.scitotenv. 2019.07.204

Fernie, A. R., and Yan, J. (2019). De novo domestication: an alternative route toward new crops for the future. Mol. Plant 12, 615-631. doi: 10.1016/j.molp. 2019.03.016

Fernie, A. R., Tadmor, Y., and Zamir, D. (2006). Natural genetic variation for improving crop quality. Curr. Opin. Plant Biol. 9, 196-202. doi: 10.1016/j.pbi. 2006.01.010

Fick, S. E., and Hijmans, R. J. (2017). WorldClim 2: new $1 \mathrm{~km}$ spatial resolution climate surfaces for global land areas. Int. J. Climatol. 37, 4302-4315. doi: 10.1002/joc.5086

Fournier-Level, A., Korte, A., Cooper, M. D., Nordborg, M., Schmitt, J., and Wilczek, A. M. (2011). A map of local adaptation in Arabidopsis thaliana. Science 334, 86-89. doi: 10.1126/science.1209271

Franco-Duran, J., Crossa, J., Chen, J., and Hearne, S. J. (2019). The impact of sample selection strategies on genetic diversity and representativeness in germplasm bank collections. BMC Plant Biol. 19:520. doi: 10.1186/s12870-0192142-y

Gayacharan., Rani, U., Singh, S., Basandrai, A. K., Rathee, V. K., Tripathi, K., Singh, N., et al. (2020). Identification of novel resistant sources for ascochyta blight (Ascochyta rabiei) in chickpea. PLoS One 15:e240589. doi: 10.1371/journal. pone.0240589

Gibson, M. J., and Moyle, L. C. (2020). Regional differences in the abiotic environment contribute to genomic divergence within a wild tomato species. Mol. Ecol. 12, 2204-2217. doi: 10.1111/mec.15477

Godfray, H. C. J., Beddington, J. R., Crute, I. R., Haddad, L., Lawrence, D., Muir, J. F., et al. (2010). Food security: the challenge of feeding 9 billion people. Science $327,812-818$.

Guerrero, J., Andrello, M., Burgarella, C., and Manel, S. (2018). Soil environment is a key driver of adaptation in Medicago truncatula: new insights from landscape genomics. N. Phytol. 219, 378-390. doi: 10.1111/nph.15171

Günther, T., and Coop, G. (2013). Robust identification of local adaptation from allele frequencies. Genetics 195, 205-220. doi: 10.1534/genetics.113.152462

Gur, A., and Zamir, D. (2004). Unused natural variation can lift yield barriers in plant breeding. PLoS Biol. 2004:e245. doi: 10.1371/journal.pbio.0020245

Hajjar, R., and Hodgkin, T. (2007). The use of wild relatives in crop improvement: a survey of developments over the last 20 years. Euphytica 156, 1-13. doi: 10.1007/s10681-007-9363-0

Hale, I., Melo, A., and Gustafson, H. (2018). Sex-linked molecular markers for two cold-hardy kiwifruit species, Actinidia arguta and A. kolomikta. Eur. J. Hortic. Sci. 83, 236-246. doi: 10.17660/ejhs.2018/83.4.4

Halewood, M., Chiurugwi, T., Sackville Hamilton, R., Kurtz, B., Marden, E., Welch, E., et al. (2018). Plant genetic resources for food and agriculture: opportunities and challenges emerging from the science and information technology revolution. N. Phytol. 217, 1407-1419. doi: 10.1111/nph.14993

Harlan, J. R., and de Wet, J. M. J. (1971). Toward a rational classification of cultivated plants. Taxon 20, 509-517. doi: 10.2307/1218252

He, F., Pasam, R., Shi, F., Kant, S., Keeble-Gagnere, G., Kay, P., et al. (2019). Exome sequencing highlights the role of wild-relative introgression in shaping the adaptive landscape of the wheat genome. Nat. Genet. 51, 896-904. doi: 10.1038/s41588-019-0382-2

Hoban, S., Kelley, J. L., Lotterhos, K. E., Antolin, M. F., Bradburd, G., Lowry, D. B., et al. (2016). Finding the genomic basis of local adaptation: pitfalls, practical solutions, and future directions. Am. Natural. 188, 379-397. doi: 10. $1086 / 688018$

Hoban, S., Volk, G., Routson, K. J., Walters, C., and Richards, C. (2018). "Sampling wild species to conserve genetic diversity," in North American Crop Wild Relatives, eds C. K. Khoury, K. A. Williams, S. L. Greene, L. F. Marek, and M. B. Kantar (Cham: Springer), 209-228. doi: 10.1007/978-3-319-95101-0_8

Hübner, S., Bercovich, N., Todesco, M., Mandel, J. R., Odenheimer, J., Ziegler, E., et al. (2019). Sunflower pan-genome analysis shows that hybridization altered gene content and disease resistance. Nat. Plants 5, 54-62. doi: 10.1038/s41477018-0329-0

Hübner, S., Korol, A. B., and Schmid, K. J. (2015). RNA-Seq analysis identifies genes associated with differential reproductive success under drought-stress in accessions of wild barley Hordeum spontaneum. BMC Plant Biol. 15:134. doi: 10.1186/s12870-015-0528-z
Iftekharuddaula, K. M., Newaz, M. A., Salam, M. A., Ahmed, H. U., Mahbub, M. A. A., Septiningsih, E. M., et al. (2011). Rapid and high-precision marker assisted backcrossing to introgress the SUB1 QTL into BR11, the rainfed lowland rice mega variety of Bangladesh. Euphytica 178, 83-97. doi: 10.1007/ s10681-010-0272-2

Jaworski, C. C., Allan, C. W., and Matzkin, L. M. (2020). Chromosome-level hybrid de novo genome assemblies as an attainable option for nonmodel insects. Mol. Ecol. Resour. 20, 1277-1293. doi: 10.1111/1755-0998.13176

Jia, K. H., Zhao, W., Maier, P. A., Hu, X. G., Jin, Y., Zhou, S. S., et al. (2019). Landscape genomics predicts climate change-related genetic offset for the widespread Platycladus orientalis (Cupressaceae). Evolut. Applicat. 13, 665-676. doi: 10.1111 /eva.12891

Jiménez-Jacinto, V., Sanchez-Flores, A., and Vega-Alvarado, L. (2019). Integrative differential expression analysis for multiple experiments (IDEAMEX): a web server tool for integrated rna-seq data analysis. Front. Genet. 10:279. doi: 10. 3389/fgene.2019.00279

Jordan, R., Dillon, S. K., Prober, S. M., and Hoffmann, A. A. (2016). Landscape genomics reveals altered genome wide diversity within revegetated stands of Eucalyptus microcarpa (Grey Box). N. Phytol. 212, 992-1006. doi: 10.1111/nph. 14084

Kantar, M. B., Khoury, C. K., Castañeda Alvarez, N. P., Kane, N., Marek, L., Sieler, G., et al. (2015). Ecogeography and utility to plant breeding of the crop wild relatives of sunflower (Helianthus annuus L.). Front. Plant Sci. 6:841. doi: 10.3389/fpls.2015.00841

Kausch, A. P., Nelson-Vasilchik, K., Hague, J., Mookkan, M., Quemada, H., Dellaporta, S., et al. (2019). Edit at will: Genotype independent plant transformation in the era of advanced genomics and genome editing. Plant Sci. 281, 186-205. doi: 10.1016/j.plantsci.2019.01.006

Kern, A. D., and Schrider, D. R. (2018). diploS/HIC: an updated approach to classifying selective sweeps. G3 Genes Genomes Genet. 8, 1959-1970. doi: 10. 1534/g3.118.200262

Khazaei, H., Street, K., Bari, A., Mackay, M., and Stoddard, F. L. (2013). The FIGS (Focused Identification of Germplasm Strategy) approach identifies traits related to drought adaptation in Vicia faba genetic resources. PLoS One 8:e63107. doi: 10.1371/journal.pone.0063107

Khoury, C. K., Bjorkman, A. D., Dempewolf, H., Ramirez-Villegas, J., Guarino, L., Jarvis, A., et al. (2014). Increasing homogeneity in global food supplies and the implications for food security. Proc. Natl. Acad. Sci. 111, 4001-4006. doi: 10.1073/pnas.1313490111

Khoury, C. K., Carver, D., Greene, S. L., Williams, K. A., Achicanoy, H. A., Schori, M., et al. (2020). Crop wild relatives of the United States require urgent conservation action. Proc. Natl. Acad. Sci. 117, 33351-33357. doi: 10.1073/pnas. 2007029117

Khoury, C. K., Castañeda-Alvarez, N. P., Achicanoy, H. A., Sosa, C. C., Bernau, V., Kassa, M. T., et al. (2015). Crop wild relatives of pigeonpea [Cajanus cajan (L.) Millsp.]: Distributions, ex situ conservation status, and potential genetic resources for abiotic stress tolerance. Biol. Conserv. 184, 259-270. doi: 10.1016/ j.biocon.2015.01.032

Korte, A., and Farlow, A. (2013). The advantages and limitations of trait analysis with GWAS: a review. Plant Methods 9, 1-9.

Ladha, J. K., Tirol-Padre, A., Reddy, C. K., Cassman, K. G., Verma, S., Powlson, D. S., et al. (2016). Global nitrogen budgets in cereals: A 50-year assessment for maize, rice and wheat production systems. Sci. Rep. 6, 1-9.

Lemmon, Z. H., Reem, N. T., Dalrymple, J., Soyk, S., Swartwood, K. E., RodriguezLeal, D., et al. (2018). Rapid improvement of domestication traits in an orphan crop by genome editing. Nat. Plants 4, 766-770. doi: 10.1038/s41477-0180259-x

Li, B., and Dewey, C. N. (2011). RSEM: accurate transcript quantification from RNA-Seq data with or without a reference genome. BMC Bioinformatics 12:323. doi: 10.1186/1471-2105-12-323

Li, W., Li, K., Huang, Y., Shi, C., Hu, W. S., Zhang, Y., et al. (2020). SMRT sequencing of the Oryza rufipogon genome reveals the genomic basis of rice adaptation. Commun. Biol. 3, 1-11.

Li, Y. H., Li, D., Jiao, Y. Q., Schnable, J. C., Li, Y. F., Li, H. H., et al. (2019). Identification of loci controlling adaptation in Chinese soya bean landraces via a combination of conventional and bioclimatic GWAS. Plant Biotechnol. J. 18, 389-401. doi: 10.1111/pbi.13206 
Lotterhos, K. E., and Whitlock, M. C. (2015). The relative power of genome scans to detect local adaptation depends on sampling design and statistical method. Mol. Ecol. 24, 1031-1046. doi: 10.1111/mec.13100

Lotterhos, K. E., Card, D. C., Schaal, S. M., Wang, L., Collins, C., and Verity, B. (2017). Composite measures of selection can improve the signal-to-noise ratio in genome scans. Methods Ecol. Evol. 8, 717-727. doi: 10.1111/2041-210x.12774

Lynch, M., and Ho, W. C. (2020). The limits to estimating population-genetic parameters with temporal data. Genome Biol. Evol. 12, 443-455. doi: 10.1093/ gbe/evaa056

Marcotuli, I., Mazzeo, A., Nigro, D., Giove, S., Giancaspro, A., Colasuonno, P., et al. (2019). Analysis of genetic diversity of Ficus carica L.(Moraceae) collection using simple sequence repeat (SSR) markers. Acta Sci. Polonorum Hortorum Cultus 18, 93-109. doi: 10.24326/asphc.2019.4.9

Maxted, N., Ford-Lloyd, B. V., Jury, S., Kell, S., and Scholten, M. (2006). Towards a definition of a crop wild relative. Biodiver. Conserv. 15, 2673-2685. doi: 10.1007/s10531-005-5409-6

McCluskey, K., Barker, K. B., Barton, H. A., Boundy-Mills, K., Brown, D. R., et al. (2017). The US Culture Collection Network responding to the requirements of the Nagoya Protocol on access and benefit sharing. MBio 8:17.

Meng, L., Zhao, X., Ponce, K., Ye, G., and Leung, H. (2016). QTL mapping for agronomic traits using multi-parent advanced generation inter-cross (MAGIC) populations derived from diverse elite indica rice lines. Field Crops Res. 189, 19-42. doi: 10.1016/j.fcr.2016.02.004

Meyer, R. S., Choi, J. Y., Sanches, M., Plessis, A., Flowers, J. M., Amas, J., et al. (2016). Domestication history and geographical adaptation inferred from a SNP map of African rice. Nature Genetics, 48, 1083-1088. doi: 10.1038/ng.3633

Meyer, R. S., DuVal, A. E., and Jensen, H. R. (2012). Patterns and processes in crop domestication: an historical review and quantitative analysis of 203 global food crops. N. Phytol. 196, 29-48. doi: 10.1111/j.1469-8137.2012.04253.x

Migicovsky, Z., and Myles, S. (2017). Exploiting wild relatives for genomicsassisted breeding of perennial crops. Front. Plant Sci. 8:460. doi: 10.3389/fpls. 2017.00460

Migicovsky, Z., Sawler, J., Money, D., Eibach, R., Miller, A. J., Luby, J. J., et al. (2016). Genomic ancestry estimation quantifies use of wild species in grape breeding. BMC Genomics 17:478. doi: 10.1186/s12864-016-2834-8

Migicovsky, Z., Warschefsky, E., Klein, L. L., and Miller, A. J. (2019). Using living germplasm collections to characterize, improve, and conserve woody perennials. Crop Sci. 59, 2365-2380. doi: 10.2135/cropsci2019.05. 0353

Miller, R. E., and Khoury, C. K. (2018). "The gene pool concept applied to crop wild relatives: An evolutionary perspective," in North American Crop Wild Relatives, eds C. K. Khoury, K. A. Williams, S. L. Greene, L. F. Marek, and M. B. Kantar (Cham: Springer), 167-188. doi: 10.1007/978-3-319-95101-0_6

Milner, S. G., Jost, M., Taketa, S., Mazón, E. R., Himmelbach, A., Oppermann, M., et al. (2019). Genebank genomics highlights the diversity of a global barley collection. Nat. Genet. 51, 319-326. doi: 10.1038/s41588-018-0266-x

Monteiro, F., Frese, L., Castro, S., Duarte, M. C., Paulo, O. S., Loureiro, J., et al. (2018). Genetic and genomic tools to asssist sugar beet improvement: the value of the crop wild relatives. Front. Plant Sci. 9:74. doi: 10.3389/fpls.2018.00074

Morris, G. P., Ramu, P., Deshpande, S. P., Hash, C. T., Shah, T., Upadhyaya, H. D., et al. (2013). Population genomic and genome-wide association studies of agroclimatic traits in sorghum. Proc. Natl. Acad. Sci. 110, 453-458. doi: $10.1073 /$ pnas. 1215985110

Morris, M., Dreher, K., Ribaut, J. M., and Khairallah, M. (2003). Money matters (II): costs of maize inbred line conversion schemes at CIMMYT using conventional and marker-assisted selection. Mol. Breeding 11, 235-247.

Mueller, N. G., Fritz, G. J., Patton, P., Carmody, S., and Horton, E. T. (2017). Growing the lost crops of eastern North America's original agricultural system. Nat. Plants 3, 1-5. doi: 10.1201/b18036-2

Mugabe, D., Coyne, C. J., Piaskowski, J., Zheng, P., Ma, Y., Landry, E., et al. (2019). Quantitative trait loci for cold tolerance in chickpea. Crop Sci. 59, 573-582. doi: 10.2135/cropsci2018.08.0504

Myers, S. S., Smith, M. R., Guth, S., Golden, C. D., Vaitla, B., Mueller, N. D., et al. (2017). Climate change and global food systems: potential impacts on food security and undernutrition. Annu. Rev. Public Health 38, 259-277. doi: 10.1146/annurev-publhealth-031816-044356

Nicholls, H. L., John, C. R., Watson, D. S., Munroe, P. B., Barnes, M. R., and Cabrera, C. P. (2020). Reaching the end-game for GWAS: Machine learning approaches for the prioritization of complex disease loci. Front. Genet. 11:350. doi: $10.3389 /$ fgene. 2020.00350

Owens, G. L., Baute, G. J., Hübner, S., and Rieseberg, L. H. (2019). Genomic sequence and copy number evolution during hybrid crop development in sunflowers. Evolut. Applicat. 12, 54-65. doi: 10.1111/eva.12603

Parker, T., y Teran, J. C. B. M., Palkovic, A., Jernstedt, J., and Gepts, P. (2019). Genetic control of pod dehiscence in domesticated common bean: Associations with range expansion and local aridity conditions. Biorxiv:517516. Preprint.

Pfeifer, B., Wittelsbürger, U., Ramos-Onsins, S. E., and Lercher, M. J. (2014). PopGenome: an efficient Swiss army knife for population genomic analyses in R. Mol. Biol. Evolut. 31, 1929-1936. doi: 10.1093/molbev/msu136

Pfeiffer, W. H., and McClafferty, B. (2007). HarvestPlus: breeding crops for better nutrition. Crop Sci. 47, S-88.

Pimentel, D., Wilson, C., Mccullum, C., Huang, R., Dwen, P., Flack, J., et al. (1997). Economic and environmental benefits of biodiversity. BioScience 47, 747-757. doi: $10.2307 / 1313097$

Pinela, J., Carvalho, A. M., and Ferreira, I. C. (2017). Wild edible plants: Nutritional and toxicological characteristics, retrieval strategies and importance for today's society. Food Chem. Toxicol. 110, 165-188. doi: 10.1016/j.fct.2017.10.020

Pironon, S., Etherington, T. R., Borrell, J. S., Kühn, N., Macias-Fauria, M., Ondo, I., et al. (2019). Potential adaptive strategies for 29 sub-Saharan crops under future climate change. Nat. Clim. Change 9, 758-763. doi: 10.1038/s41558-0190585-7

Privé, F., Luu, K., Vilhjálmsson, B. J., and Blum, M. G. (2020). Performing highly efficient genome scans for local adaptation with $\mathrm{R}$ package pcadapt version 4 . Mol. Biol. Evol. 37, 2153-2154. doi: 10.1093/molbev/msaa053

Prohens, J., Gramazio, P., Plazas, M., Dempewolf, H., Kilian, B., Díez, M. J., et al. (2017). Introgressiomics: a new approach for using crop wild relatives in breeding for adaptation to climate change. Euphytica 213:158.

Purugganan, M. D. (2019). Evolutionary insights into the nature of plant domestication. Curr. Biol. 29, R705-R714.

Pyhäjärvi, T., Hufford, M. B., Mezmouk, S., and Ross-Ibarra, J. (2013). Complex patterns of local adaptation in teosinte. Genome Biol. Evol. 5, 1594-1609. doi: 10.1093/gbe/evt109

Qi, L. L., Foley, M. E., Cai, X. W., and Gulya, T. J. (2016). Genetics and mapping of a novel downy mildew resistance gene, $\mathrm{Pl} 18$, introgressed from wild Helianthus argophyllus into cultivated sunflower (Helianthus annuus L.). Theoret. Appl. Genet. 129, 741-752. doi: 10.1007/s00122-015-2662-2

Qi, L. L., Ma, G. J., Li, X. H., and Seiler, G. J. (2019). Diversification of the downy mildew resistance gene pool by introgression of a new gene, $\mathrm{Pl} 35$, from wild Helianthus argophyllus into oilseed and confection sunflowers (Helianthus annuus L.). Theoret. Appl. Genet. 132, 2553-2565. doi: 10.1007/s00122-01903370-9

Qiu, J., Zhou, Y., Mao, L., Ye, C., Wang, W., Zhang, J., et al. (2017). Genomic variation associated with local adaptation of weedy rice during dedomestication. Nat. Commun. 8, 1-12.

Ramstein, G. P., Jensen, S. E., and Buckler, E. S. (2019). Breaking the curse of dimensionality to identify causal variants in Breeding 4. Theoret. Appl. Genet. 132, 559-567. doi: 10.1007/s00122-018-3267-3

Rathinam, M., Mishra, P., Vasudevan, M., Budhwar, R., Mahato, A., Prabha, A. L., et al. (2019). Comparative transcriptome analysis of pigeonpea, Cajanus cajan (L.) and one of its wild relatives Cajanus platycarpus (Benth.) Maesen. PLoS One 14:e0218731. doi: 10.1371/journal.pone.0218731

Raubach, S., Kilian, B., Dreher, K., Amri, A., Bassi, F. M., Boukar, O., et al. (2020). From bits to bites: Advancement of the Germinate platform to support prebreeding informatics for crop wild relatives. Crop Sci.:20248. Inpress.

Ray, D. K., West, P. C., Clark, M., Gerber, J. S., Prishchepov, A. V., and Chatterjee, S. (2019). Climate change has likely already affected global food production. PLoS One 14:217148. doi: 10.1371/journal.pone.0217148

Rebetzke, G. J., Jimenez-Berni, J., Fischer, R. A., Deery, D. M., and Smith, D. J. (2019). High-throughput phenotyping to enhance the use of crop genetic resources. Plant Sci. 282, 40-48. doi: 10.1016/j.plantsci.2018.06.017

Rellstab, C., Gugerli, F., Eckert, A. J., Hancock, A. M., and Holderegger, R. (2015). A practical guide to environmental association analysis in landscape genomics. Mol. Ecol. 24, 4348-4370. doi: 10.1111/mec.13322

Rieseberg, L. H., Van Fossen, C., Arias, D., and Carter, R. L. (1994). Cytoplasmic male sterility in sunflower: origin, inheritance, and frequency in natural 
populations. J. Heredity 85, 233-238. doi: 10.1093/oxfordjournals.jhered. a111443

Rodgers-Melnick, E., Bradbury, P. J., Elshire, R. J., Glaubitz, J. C., Acharya, C. B., Mitchell, S. E., et al. (2015). Recombination in diverse maize is stable, predictable, and associated with genetic load. Proc. Natl. Acad. Sci. 112, 38233828. doi: 10.1073/pnas.1413864112

Rosyara, U. R., De Jong, W. S., Douches, D. S., and Endelman, J. B. (2016). Software for genome-wide association studies in autopolyploids and its application to potato. Plant Genome 9, 1-10.

Russell, J., Mascher, M., Dawson, I. K., Kyriakidis, S., Calixto, C., Freund, F., et al. (2016). Exome sequencing of geographically diverse barley landraces and wild relatives gives insights into environmental adaptation. Nat. Genet. 48:1024. doi: 10.1038/ng.3612

Sachdeva, H., and Barton, N. H. (2018). Replicability of introgression under linked, polygenic selection. Genetics 210, 1411-1427. doi: 10.1534/genetics.118.301429

Schrider, D. R., and Kern, A. D. (2018). Supervised machine learning for population genetics: a new paradigm. Trends Genet. 34, 301-312. doi: 10.1016/j.tig.2017.12. 005

Selmoni, O., Vajana, E., Guillaume, A., Rochat, E., and Joost, S. (2020). Sampling strategy optimization to increase statistical power in landscape genomics: A simulation-based approach. Mol. Ecol. Resour. 20, 154-169. doi: 10.1111/17550998.13095

Sharma, S., and Upadhyaya, H. D. (2016). Pre-breeding to expand primary genepool through introgression of genes from wild Cajanus species for pigeonpea improvement. Legume Perspect. 17-20.

Sherman, B., and Henry, R. J. (2020). The Nagoya Protocol and historical collections of plants. Nat. Plants 6, 430-432. doi: 10.1038/s41477-020-0657-8

Singh, R. J. (2019). Cytogenetics and genetic introgression from wild relatives in soybean. Nucleus 62, 3-14. doi: 10.1007/s13237-019-00263-6

Sork, V. L., Squire, K., Gugger, P. F., Steele, S. E., Levy, E. D., and Eckert, A. J. (2016). Landscape genomic analysis of candidate genes for climate adaptation in a California endemic oak, Quercus lobata. Am. J. Bot. 103, 33-46. doi: 10.3732/ajb.1500162

Stetter, M. G., Gates, D. J., Mei, W., and Ross-Ibarra, J. (2017). How to make a domesticate. Curr. Biol. 27, R896-R900.

Stinchcombe, J. R., and Hoekstra, H. E. (2008). Combining population genomics and quantitative genetics: finding the genes underlying ecologically important traits. Heredity 100, 158-170. doi: 10.1038/sj.hdy.6800937

Syfert, M. M., Castañeda-Álvarez, N. P., Khoury, C. K., Särkinen, T., Sosa, C. C., Achicanoy, H. A., et al. (2016). Crop wild relatives of the brinjal eggplant (Solanum melongena): Poorly represented in genebanks and many species at risk of extinction. Am. J. Bot. 103, 635-651. doi: 10.3732/ajb.1500539

Szymañski, J., Bocobza, S., Panda, S., Sonawane, P., Cárdenas, P. D., Lashbrooke, J., et al. (2020). Analysis of wild tomato introgression lines elucidates the genetic basis of transcriptome and metabolome variation underlying fruit traits and pathogen response. Nat. Genet. 52, 1111-1121. doi: 10.1038/s41588-020-0690-6

Tang, Y., Liu, X., Wang, J., Li, M., Wang, Q., Tian, F., et al. (2016). GAPIT version 2: an enhanced integrated tool for genomic association and prediction. Plant Genome 9, 1-9.

Tanksley, S. D., and McCouch, S. R. (1997). Seed banks and molecular maps: unlocking genetic potential from the wild. Science 277, 1063-1066. doi: 10.1126/ science.277.5329.1063

Tao, Y., Zhao, X., Mace, E., Henry, R., and Jordan, D. (2019). Exploring and exploiting pan-genomics for crop improvement. Mol. Plant 12, 156-169. doi: 10.1016/j.molp.2018.12.016

Tardieu, F., Cabrera-Bosquet, L., Pridmore, T., and Bennett, M. (2017). Plant phenomics, from sensors to knowledge. Curr. Biol. 27, R770-R783.

Todesco, M., Owens, G. L., Bercovich, N., Légaré, J. S., Soudi, S., Burge, D. O., et al. (2020). Massive haplotypes underlie ecotypic differentiation in sunflowers. Nature 584, 602-607. doi: 10.1038/s41586-020-2467-6

Torada, L., Lorenzon, L., Beddis, A., Isildak, U., Pattini, L., Mathieson, S., et al. (2019). ImaGene: a convolutional neural network to quantify natural selection from genomic data. BMC Bioinformatics 20:337. doi: 10.1186/s12859-0192927-x
Viruel, J., Kantar, M. B., Gargiulo, R., Hesketh-Prichard, P., Leong, N., Cockel, C., et al. (2020). Crop wild phylorelatives (CWPs): Phylogenetic distance, cytogenetic compatibility and breeding system data enable estimation of crop wild relative gene pool classification. Botanic. J. Linnean Soc. 195, 1-33. doi: 10.1093/botlinnean/boaa064

Voichek, Y., and Weigel, D. (2020). Identifying genetic variants underlying phenotypic variation in plants without complete genomes. Nat. Genet. 52, 534-540. doi: 10.1038/s41588-020-0612-7

Walkowiak, S., Gao, L., Monat, C., Haberer, G., Kassa, M. T., Brinton, J., et al. (2020). Multiple wheat genomes reveal global variation in modern breeding. Nature 588, 277-283.

Wang, B., Zhu, L., Zhao, B., Zhao, Y., Xie, Y., Zheng, Z., et al. (2019). Development of a haploid-inducer mediated genome editing system for accelerating maize breeding. Mol. Plant 12, 597-602. doi: 10.1016/j.molp.2019.03.006

Wang, P., Luo, Y., Huang, J., Gao, S., Zhu, G., Dang, Z., et al. (2020). The genome evolution and domestication of tropical fruit mango. Genome Biol. 21, 1-17.

Warburton, M. L., Rauf, S., Marek, L., Hussain, M., Ogunola, O., de Jesus Sanchez, et al. (2017). The use of crop wild relatives in maize and sunflower breeding. Crop Sci. 57, 1227-1240. doi: 10.2135/cropsci2016.10.0855

Warschefsky, E. J., and von Wettberg, E. J. (2019). Population genomic analysis of mango (Mangifera indica) suggests a complex history of domestication. N. Phytol. 222, 2023-2037. doi: 10.1111/nph.15731

Williams, J. N., Seo, C., Thorne, J., Nelson, J. K., Erwin, S., O’Brien, J. M., et al. (2009). Using species distribution models to predict new occurrences for rare plants. Divers. Distribut. 15, 565-576. doi: 10.1111/j.1472-4642.2009.00567.x

Wright, S. I., and Gaut, B. S. (2005). Molecular population genetics and the search for adaptive evolution in plants. Mol. Biol. Evol. 22, 506-519. doi: 10.1093/ molbev/msi035

Xiao, J. H., Grandillo, S., Ahn, S. N., McCouch, S. R., Tanksley, S. D., Liu, J. M., et al. (1996). Genes from wild rice improve yield. Nature. 384, 223-224. doi: $10.1038 / 384223 \mathrm{a} 0$

Xu, K., Xu, X., Fukao, T., Canlas, P., Maghirang-Rodriguez, R., Heuer, S., et al. (2006). Sub1A is an ethylene-response-factor-like gene that confers submergence tolerance to rice. Nature 442, 705-708. doi: 10.1038/nature04920

Yang, W., Feng, H., Zhang, X., Zhang, J., Doonan, J. H., Batchelor, W. D., et al. (2020). Crop phenomics and high-throughput phenotyping: Past decades, current challenges, and future perspectives. Mol. Plant 13, 187-214. doi: 10. 1016/j.molp.2020.01.008

Yoder, J. B., Stanton-Geddes, J., Zhou, P., Briskine, R., Young, N. D., et al. (2014). Genomic signature of adaptation to climate in Medicago truncatula. Genetics 196, 1263-1275. doi: 10.1534/genetics.113.159319

Zamir, D. (2001). Improving plant breeding with exotic genetic libraries. Nat. Rev. Genet. 2, 983-989. doi: 10.1038/35103590

Zhang, R., Sun, B., Chen, J., Cao, A., Xing, L., Feng, Y., et al. (2016). Pm55, a developmental-stage and tissue-specific powdery mildew resistance gene introgressed from Dasypyrum villosum into common wheat. Theoret. Appl. Genet. 129, 1975-1984. doi: 10.1007/s00122-016-2753-8

Zhou, X., and Stephens, M. (2014). Efficient multivariate linear mixed model algorithms for genome-wide association studies. Nat. Methods 11, 407-409. doi: $10.1038 /$ nmeth. 2848

Zhou, Y., Minio, A., Massonnet, M., Solares, E., Lv, Y., Beridze, T., et al. (2019). The population genetics of structural variants in grapevine domestication. Nat. Plants 5, 965-979. doi: 10.1038/s41477-019-0507-8

Conflict of Interest: The authors declare that the research was conducted in the absence of any commercial or financial relationships that could be construed as a potential conflict of interest.

Copyright (C) 2021 Hübner and Kantar. This is an open-access article distributed under the terms of the Creative Commons Attribution License (CC BY). The use, distribution or reproduction in other forums is permitted, provided the original author(s) and the copyright owner(s) are credited and that the original publication in this journal is cited, in accordance with accepted academic practice. No use, distribution or reproduction is permitted which does not comply with these terms. 